\title{
3D-Lasersintern metallischer Werkstoffe
}

Im Flugzeugbau zählt jedes Gramm. Doch Anforderungen an die Sicherheit und konstruktionsbedingte Einschränkungen setzen dem Willen zur Gewichtsreduktion Grenzen. Diese sollen nun durch einen neuartigen dreidimensionalen Fertigungsprozess, dem Metall-Lasersintern, verschoben werden, erläutert das österreichische Unternehmen Fotec Forschungsund Technologietransfer. Das österreichweit einzige - und weltweit zweite - Gerät für dieses Verfahren steht derzeit bei der Firma in der Wiener Neustadt. Das Forschungsunternehmen der dortigen Fachhochschule optimiert aktuell die Kontrolle und Qualitätssicherung des Produktionsprozesses - und stellt nach eigenen Angaben darüber hinaus einen Treibstoffsammler für einen Flugzeugmotor her, der um $77 \%$ leichter sei als bisher.

„Mit dem Lasersintern konnten wir die Anzahl an Bauteilen von fünf auf einen verrin- gern. Damit ging auch die Gewichtsreduktion einher", sagt Fotec-Geschäftsführer, Dr. Gerhard Pramhas." Ausgangsstoff beim Metall-Lasersintern ist ein metallisches Pulver. Mechanisch wird dieses schichtweise zu einem Pulverbett aufgebaut. Nach jedem Schichtauftrag wird das Pulver an definierten Stellen durch einen Laser verschmolzen. Anschließend wird eine weitere Pulverschicht aufgetragen und erneut an den vorausberechneten Stellen zum Schmelzen gebracht. So lassen sich Schicht für Schicht komplexe Bauteile in einem Stück fertigen. Im Prinzip handelt es sich dabei um einen Rapid-Prototyping-Prozess, der hier aber mittels Laser in Metall ausgeführt wird.

Der Treibstoffsammler hat bislang aus fünf an der Drehbank produzierten Einzelteilen bestanden, die anschließend klassisch verschweißt wurden. Die Teile sind dabei zum Teil hohl, um den Treibstoffdurchfluss zu ermöglichen. Eine der Komponenten hat zusätzlich ein Gewinde, dessen Herstellung einen eigenen Produktionsschritt erforderte. Beim Metall-Lasersintern konnte der gesam- te Treibstoffsammler, mit Hohlräumen und Gewinde, in einem Schritt hergestellt werden. Die Produktionsgenauigkeit liegt dabei nach Angaben von Pramhas im Mikrometerbereich und neben dem Gewicht ließ sich auch das Volumen des Treibstoffsammlers um fast $60 \%$ vermindern.

Obwohl die Anlage bei Fotec tatsächlich zur industriellen Fertigung geeignet ist, liegt der aktuelle Tätigkeitsfokus woanders, wie Pramhas erläutert: „Die Qualität des Prozesses hängt stark vom optimalen Laserschmelzprozess ab. Zu dessen Kontrolle möchten wir ein optisches Verfahren entwickeln, das während des laufenden Produktionsprozesses arbeitet. In einer weiteren Entwicklungsstufe soll dieses dann auch einmal direkt Informationen an einen adaptiven Steuerungsprozess liefern, sodass die Qualität der Werkstücke auch bei größeren Stückzahlen gleichbleibend hoch ist." Denn obwohl das Metall-Lasersintern sich eher für die Produktion von Einzelstücken eigne, sollen sich Stückzahlen von mehreren Hundert pro Jahr durchaus realisieren lassen.

\section{Mit Magnesium Gewicht einsparen}

Der amerikanische Automobilhersteller General Motors (GM) möchte den Einsatz von massearmen Teilen in Fahrzeugen ausweiten. Das Unternehmen entwickelt und testet derzeit ein Warmumformverfahren in Verbindung mit einem Verfahren zur Vorbeugung von Korrosion für Magnesiumblech. Mithilfe dieser Prozesse soll der verstärkte Einsatz dieser hochfesten Alternative zu Stahl und Aluminium möglich werden.

Bei dem patentierten Prozess von GM wird das Magnesium auf $450{ }^{\circ} \mathrm{C}$ erhitzt. Bei dieser Temperatur soll sich das Material gut verformen lassen, das Ergebnis seien formstabile und steife Formteile. Mithilfe dieses Prozesses hat GM eine praktisch serienreife Magne-
sium-Innenversteifung eines Kofferraumdeckels entwickelt, "die 77.000 robotergesteuerte Schläge sowie 250-kg-Aufpralle ohne Probleme überstanden" habe. Mithilfe dieses Bauteils könne GM 1 kg Gewicwht im Vergleich zur Verwendung des Gegenstücks aus Aluminium einsparen.

GM hat bereits die Korrosionsbeständigkeit seines behandelten Magnesiumsblechs ge-

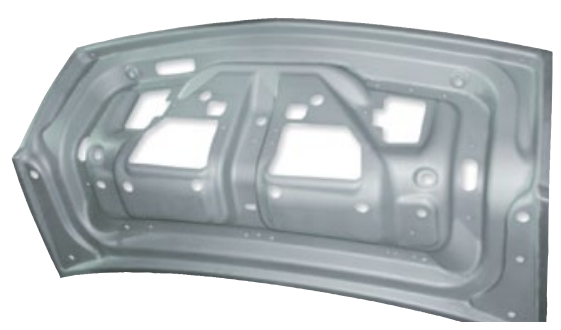

testet. Das Material habe in einem zehnwöchigen Dauertest Umweltbedingungen wie Salznebel, hoher Luftfeuchtigkeit und extreme Temperaturen stand gehalten. Wie das Magnesium korrosionsbeständig gemacht wird, verrät GM jedoch nicht.

BMW M beschäftigt sich ebenfalls in einem Vorentwicklungsprojekt mit Magnesium. So präsentierte das deutsche Unternehmen eine Rücksitzlehne, die aus Magnesium bestehen könnte. Die Magnesiumdurchlade aus dem Vorentwicklungsprojekt erreicht mit einem Gewicht von 5,45 kg eine Gewichtseinsparung von mehr als 50 \% gegenüber einer Rücksitzlehne in Stahlbauweise. 